\title{
Studies of the anionic micelles effect on photogalvanic cells for solar energy conversion and storage in Sodium lauryl sulphate-Safranine-D-Xylose system
}

\author{
Prem Prakash Solanki ${ }^{*}$, K M Gangotri ${ }^{2}$ \\ ${ }^{1}$ Department of Chemistry, Faculty of Science, Banaras Hindu University, Varanasi-221005, INDIA \\ 2 Solar Energy Laboratory, Department of Chemistry, Jai Narain Vyas University, Jodhpur-342005, INDIA \\ * Corresponding author. Tel: +542 6702469, Fax: +291 2614162, E-mail: ppsolankibhu@gmail.com
}

\begin{abstract}
The Sodium lauryl sulphate (NaLS) has been used as anionic micelle species, Safranine as photosensitizer and D-Xylose as electron donor for the enhancement of the electrical output and performance (storage capacity) of the photogalvanic cell with reduce the cost of construction for commercial viability. The photopotential and photocurrent generated were $893.0 \mathrm{mV}$ and $207.0 \mu \mathrm{A}$, respectively. The observed conversion efficiency and the fill factor were $0.6800 \%$ and 0.3233 , respectively at the power point of the cell. The photogalvanic cell can be used for 98.0 minutes in the dark.The effect of different parameters like concentration of micelles; photosensitizer and electron donor, variation of $\mathrm{pH}$, light intensity and diffusion path length were observed. A current - voltage (i-V) characteristics of the photogalvanic cell was studied experimentally and a mechanism has also been proposed for the generation of the photocurrent. All observed results of the system were lower in absence of the micelles species.
\end{abstract}

Keywords: Photogalvanic cell, Micelles effect, Safranine, D-Xylose, Conversion efficiency

\section{Nomenclature}

$i_{e q} \quad$ photocurrent at equilibrium..................... $\mathrm{A}$

$i_{\max }$ maximum photocurrent...........................

$i_{p p} \quad$ photocurrent at power point ....................

$i_{s c} \quad$ short circuit current................................

pp power point .........................................

$\begin{array}{ll}M & \text { Concentration in molarity........................ } \\ t_{1 / 2} & \text { performance (storage capacity) ..............min } \\ V_{o c} & \text { open circuit voltage ................................ mV } \\ V_{p p} & \text { photopotential at power point ............... mV } \\ \eta & \text { Fill fact }\end{array}$

\section{Introduction}

The flow of current between two unsymmetrical illuminated metal electrodes in sunlight was first observed by Becquerel ${ }^{1}$ in 1839 and photogalvanic effect was first reported by Rideal and Williams ${ }^{2}$ in 1925 but, it was systematically investigated by Rabinowitch ${ }^{3}$ for ironthionine system.

The photogalvanic and photovoltaic effects with anodized zirconium and niobium electrodes were observed by Graven et al. ${ }^{4}$ while the photogalvanic effect with semiconductor anode was reported by Hall et al. ${ }^{5}$.

Electron transfer via organic dye molecule and photo-induced electron transfer between micelle and thionine dye through a charge transfer interaction have observed by Alfredo et al. ${ }^{6}$ and Mukhopadhyay and Bhowmik .

Bisquert et al. ${ }^{8}$ have reported the physical-chemical principle of dye-sensitized solar cells, and Mayer $^{9}$ has presented the molecular approaches to solar energy conversion with coordination compounds. 
Ameta et al. ${ }^{10}$ Khamesara et al. ${ }^{11}$ Pramila and Gangotri ${ }^{12}$, Gangotri and Gangotri ${ }^{13}$, and Genwa and genwa ${ }^{14}$ have used miceller species with different photosensitizer and reductant in photogalvanic system for solar energy conversion and storage.

Jana and Bhowmik ${ }^{15}$, Gangotri and $\mathrm{Lal}^{16}$ and $\mathrm{Lal}^{17}$ have used mixed dyes while Dube ${ }^{18}$ and Gangotri and Indora ${ }^{19}$ have used mixed reductant with different photosentizer in the photogalvanic systems.

Recently Genwa et $\mathrm{al}^{20}$ Gangotri and Gangotri ${ }^{21}$, Yadav and Lal ${ }^{22}$, Gangotri and Bhimwal ${ }^{23}$, Gangotri et al. ${ }^{24}$ and Gangotri and Solanki ${ }^{25}$ have developed some intrested photogalvanic cells with reasonable electrical output for solar energy conversion and storage.

They have used different photosensitizes, reductant and surfactants in photogalvanic cells but no attention has been paid to use Sodium lauryl sulphate-Safranine-D-Xylose system to enhance the electrical output and storage capacity of the cell. Our study reveals that a system of Sodium lauryl sulphate-Safranine-D-Xylose gives higher electrical output with better storage capacity, in addition, the cell is cost effective which makes it suitable for commercialization in near future, therefore, the present work was undertaken.

\section{Methodology}

All the solutions were prepared in doubly distilled water and the stock solutions of all the chemicals were prepared by direct weighing and were kept in coloured container to protect them from light. A mixture of known amounts of solution of Safranine, D-Xylose, Sodium lauryl sulphate and Sodium hydroxide were taken in an $\mathrm{H}$-shaped glass tube. The total volume of the mixture was always kept at $25.0 \mathrm{~mL}$ with make up by doubly distilled water. A platinum electrode $\left(1.0 \times 1.0 \mathrm{~cm}^{2}\right)$ was immersed in one limb of the H-tube having a window and a saturated calomel electrode was immersed in the other limb. The terminals of the electrodes were connected to a digital $\mathrm{pH}$ meter (Systronics -335) and a microammeter as shown in Fig. 1.

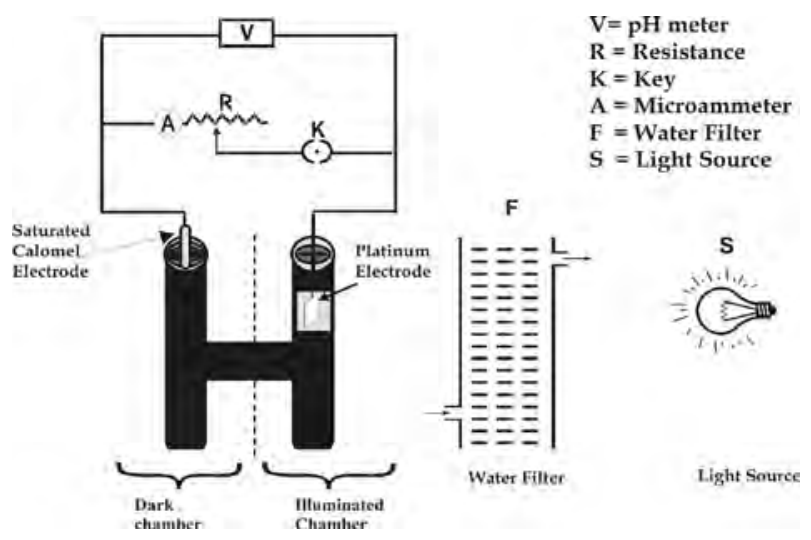

Fig.1. Experimental set up of photogalvanic cell

The whole system was first placed in the dark till a stable potential was obtained. Then, the limb having platinum electrode (whole platinum electrode area) was exposed to a $200 \mathrm{~W}$ tungsten bulb (Sylvania) while other limb having the saturated calomel electrode was kept in dark. A water filter was used to avoid thermal radiations. On illumination, the photochemical bleaching of photosensitizer was studied potentiometrically. The current-voltage (i-V) characteristics of the cell were studied by using an external load with the help of a carbon pot $(\log 470 \mathrm{~K})$ connected in the circuit. 


\section{Results and discussions}

\subsection{Effect of variation of photosensitizer and reductant concentration}

The electrical output of the cell was affected by variation of photosensitizer (Safranine) and reductant (D-Xylose) concentration. The results are summarized in Table 1.It was observed that on increasing the concentration of safranine, electrical parameters photopotential $(\Delta \mathrm{V})$ and photocurrent $\left(\mathrm{i}_{\mathrm{sc}}\right)$ increases, which reaches a maximum value at a concentration $4.60 \mathrm{X}$ $10^{-5} \mathrm{M}$, above which both parameters decrease. A lower concentration of safranine ([Safranine $]<4.60 \times 10^{-5} \mathrm{M}$ ) resulted into a decrease in electrical parameters because limited number of photosensitizer molecule were available for the excitation and consecutive donation of the electrons to the platinum electrode whereas a higher concentration of safranine ([Safranine] $>4.60 \times 10^{-5} \mathrm{M}$ ) again resulted into a decrease into electrical output as the intensity of light reaching the photosensitizer molecule near the electrode decreased due to absorption of the major portion of the light by photosensitizer molecules present in the path.

Table 1: Effect of variation of various parameters concentrations on the electrical output

\begin{tabular}{cccc}
\hline Parameters & Photopotential $(\mathrm{mV})$ & Photocurrent $(\mu \mathrm{A})$ & Power $(\mu \mathrm{W})$ \\
\hline [NaLS] X $10^{3}$ & & & \\
5.56 & 791.0 & 170.0 & 134.47 \\
5.60 & 827.0 & 189.0 & 156.30 \\
5.64 & 893.0 & 207.0 & 184.85 \\
5.68 & 837.0 & 186.0 & 155.68 \\
6.72 & 796.0 & 164.0 & 130.54 \\
[Safranine]X10 $\mathrm{M}$ & & & \\
4.48 & 803.0 & 177.0 & 142.13 \\
4.54 & 843.0 & 192.0 & 161.86 \\
4.60 & 893.0 & 207.0 & 184.85 \\
4.66 & 837.0 & 189.0 & 158.19 \\
4.72 & 800.0 & 169.0 & 135.20 \\
[D-Xylose]X10 ${ }^{3} \mathrm{M}$ & & & 123.48 \\
1.34 & 767.0 & 161.0 & 151.15 \\
1.38 & 817.0 & 185.0 & 184.85 \\
1.42 & 893.0 & 207.0 & 147.60 \\
1.56 & 820.0 & 180.0 & 121.98 \\
pH & 777.0 & 157.0 & 146.24 \\
12.66 & & & 165.55 \\
12.68 & 817.0 & 179.0 & 184.85 \\
12.70 & 849.0 & 195.0 & 161.28 \\
12.72 & 893.0 & 207.0 & 142.91 \\
12.74 & 840.0 & 192.0 & \\
\hline
\end{tabular}

A simillar result was observed for variation of the concentration of reductant. A lower concentration of reducing agent $\left([\mathrm{D}-\mathrm{Xyl}\right.$ lose $\left.]<1.42 \times 10^{-3} \mathrm{M}\right)$ resulted into a fall in electrical output because fewer reducing agent molecule were available for electron donation to the photosensitizer molecules whereas a higher concentration of reducing agent ([D-Xylose] > $1.42 \times 10^{-3} \mathrm{M}$ ) again resulted in a fall in a electrical output because the larger number of reducing agent molecule hinder the photosensitizer molecule from reaching the electrode in the desired time limit. 


\subsection{Effect of variation of micelles concentration}

The electrical output of the cell was found to increase on increasing the concentration of NaLS, reaching a maximum value at the concentration $5.64 \times 10^{-3} \mathrm{M}$, and then, further increase in their concentration a decrease in electrical output of the cell was observed. The observed results are summarized in Table 1

It was observed that maximum electrical output obtain from the cell around their critical micelle concentration (CMC) of the surfactant. It indicates the presence of the some charge transfer interaction between the dye-surfactant and the photoejection of electron from dyesurfactant depends on the charge on micelle. The surfactant has not only solublized the dye molecules to a maximum extent and their cmc value but have stabilizes also the system. In present work, the photogalvanic cell containing micelles system was compared with the cell containing photosensitizer and reductant sysem only (without micelles). The results are summerized in the Table 2.

Table 2: A comparative study of electrical parameters of the photogalvanic systems (With \& without micelles)

\begin{tabular}{|c|c|c|c|}
\hline \multirow{2}{*}{ S. No. } & \multirow{2}{*}{ Electrical parameters } & \multicolumn{2}{|c|}{ Observed Values } \\
\hline & & With Micelles $^{1}$ & Without micelles $^{2}$ \\
\hline 1. & Open circuit potential $\left(\mathrm{V}_{\mathrm{OC}}\right)$ & $1057.0 \mathrm{mV}$ & $917.0 \mathrm{mV}$ \\
\hline 2. & Short circuit current $\left(\mathrm{i}_{\mathrm{sc}}\right)$ & $207.0 \mu \mathrm{A}$ & $167.0 \mu \mathrm{A}$ \\
\hline 3. & Photopotential $(\Delta V)$ & $893.0 \mathrm{mV}$ & $743.0 \mathrm{mV}$ \\
\hline 4. & Maximum photocurrent $\left(\mathrm{i}_{\max }\right)$ & $337.0 \mu \mathrm{A}$ & $247.0 \mu \mathrm{A}$ \\
\hline 5. & Charging time & $110.0 \mathrm{~min}$. & $150.0 \mathrm{~min}$. \\
\hline 6 & Rate of fall in photopotential & $15.26 \mathrm{mV} \mathrm{min.} .^{-1}$ & $15.20 \mathrm{mV} \mathrm{min}^{-1}$ \\
\hline 7. & $\begin{array}{c}\text { Rate of initial generation of } \\
\text { photocurrent }\end{array}$ & $19.92 \mu \mathrm{A} \mathrm{min} .^{-1}$ & $16.26 \mu \mathrm{A} \min ^{-1}$ \\
\hline 8. & Power at power point (pp) & $70.74 \mu \mathrm{A}$ & $54.54 \mu \mathrm{A}$ \\
\hline 9. & Fill factor & 0.3233 & 0.2478 \\
\hline 10. & Conversion efficiency & $0.6800 \%$ & $0.4426 \%$ \\
\hline 11. & Performance of the cell, $t_{1 / 2}$ & $98.0 \mathrm{~min}$. & $87.0 \mathrm{~min}$. \\
\hline
\end{tabular}

\subsection{Effect of variation of $\mathrm{pH}$}

It was observed that there is an increase in the electrical output of the cell with increase in $\mathrm{pH}$ values and maximum value reaches at a particular $\mathrm{pH}$ value $(\mathrm{pH}=12.70)$. On further increasing in the $\mathrm{pH}$ value, a decrease in the electrical output of the cell was observed. The results are summarized in the Table 1

It is quite interesting to observe that the $\mathrm{pH}$ at the optimum condition for the reductant has a relation with its $\mathrm{pKa}$ value, i.e. the desired $\mathrm{pH}$ value should be slightly higher then their $\mathrm{pKa}$ value ( $\mathrm{pH}>\mathrm{pKa}$ ), this may be due to the availability of the reductant in an anionic form, which is a better electron donor then its unionized form.

\footnotetext{
${ }^{1}[\mathrm{NaLS}]=5.64 \times 10^{-3} \mathrm{M}$, [Safranine] $=4.60 \times 10^{-5} \mathrm{M} ;[\mathrm{D}-\mathrm{Xylose}]=1.42 \times 10^{-3} \mathrm{M} ; \mathrm{pH}=12.70$; Light intensity $=10.4 \mathrm{~mW} \mathrm{~cm}{ }^{-2}$; Temperature $=303 \mathrm{~K}$

${ }^{2}$; [Safranine] $=4.32 \times 10^{-5} \mathrm{M}$; [D-Xylose $]=1.40 \times 10^{-3} \mathrm{M} ; \mathrm{pH}=12.92 ;$ Light intensity $=10.4 \mathrm{~mW} \mathrm{~cm}^{-2}$; Temperature $=303 \mathrm{~K}$
} 


\subsection{Effect of diffusion path length}

The effect of variation of diffusion path length on the electrical output and initial rate of generation of different photocurrent of the cell was studied by using H-shaped cell of different dimensions. The results are summerized in Table 3.

Table 3: Effect of diffusion path length

\begin{tabular}{cccc}
\hline $\begin{array}{c}\text { Diffusion } \\
\text { path length } \\
\mathrm{D}_{\mathrm{L}}(\mathrm{mm})\end{array}$ & $\begin{array}{c}\text { Maximum } \\
\text { photocurrent } \\
\mathrm{i}_{\max }(\mu \mathrm{A})\end{array}$ & $\begin{array}{c}\text { Equilibrium } \\
\text { photocurrent } \\
\mathrm{i}_{\text {eq }}(\mu \mathrm{A})\end{array}$ & $\begin{array}{c}\text { Rate of initial } \\
\text { generation of } \\
\left.\text { current }(\mu \mathrm{A} \mathrm{min})^{-1}\right)\end{array}$ \\
\hline 35.0 & 329.0 & 213.0 & 17.25 \\
40.0 & 333.0 & 210.0 & 18.82 \\
45.0 & 337.0 & 207.0 & 19.12 \\
50.0 & 340.0 & 205.0 & 19.92 \\
55.0 & 342.0 & 202.0 & 20.24 \\
\hline
\end{tabular}

It was observed that in first few minutes of illumination there was a sharp increase in photocurrent and there was a gradual decrease to a stable value of photocurrent. This photocurrent at equilibrium state is known as equilibrium photocurrent $\left(\mathrm{i}_{\mathrm{eq}}\right)$. This kind of photocurrent behaviour is due to an initial rapid reaction followed by a slow rate-determining step at later stage. On the basis of effect of diffusion path length on the current parameters, it may be concluded that the leuco or semi reduced form of dyes and dyes itself are the main electroactive species at the illuminated and the dark electrodes, respectively. However, the reducing agent and their oxidized products behave as the electron carriers in the cell diffusing through the path.

\subsection{Current-voltage (i-V) characteristics of the cell}

The open circuit voltage $\left(\mathrm{V}_{\mathrm{oc}}\right)$ and short circuit current $\left(\mathrm{i}_{\mathrm{sc}}\right)$ of the cell were measured with the help of a digital pH meter (keeping the circuit open) and with a micrometer (keeping the circuit closed), respectively. The potential and current values in between these two extreme values $\left(\mathrm{V}_{\text {oc }}\right.$ and $\left.\mathrm{i}_{\mathrm{sc}}\right)$ were recorded with the help of a carbon pot $(\log 470 \mathrm{~K})$ that was in the circuit of the microammeter and through which an external load was applied. The current voltage (i-V) characteristic of the cell is shown in Fig. 2.

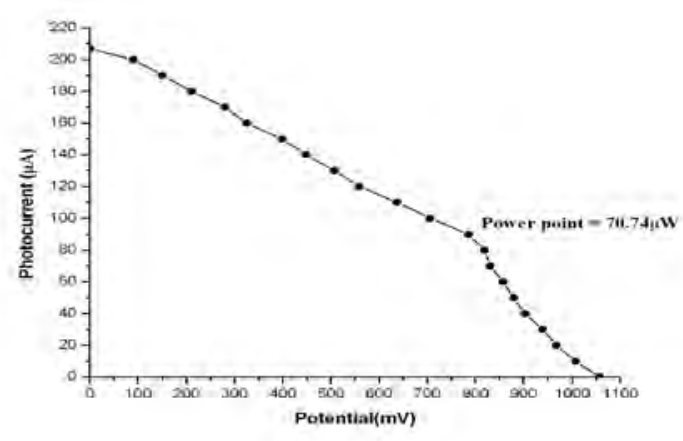

Fig. 2. Current-voltage (i-V) curve of the photogalvanic cell

It was observed that $\mathrm{i}-\mathrm{V}$ curve for the cell deviated from their regular rectangular shape. A point in the $\mathrm{i}-\mathrm{V}$ curve, known as power point (pp), was determined where the product of potential and current was maximum. With the help of the curve; fill factor ( $\eta$ ) value 0.3233 was calculated using the following formula: 


$$
\text { Fill factor }(\eta)=\frac{\mathrm{V}_{\mathrm{pp}} \times \mathrm{i}_{\mathrm{pp}}}{\mathrm{V}_{\mathrm{oc}} \times \mathrm{i}_{\mathrm{sc}}}
$$

Where $V_{p p}$ and $i_{p p}$ represent the value of potential and the current at the power point, respectively, and $\mathrm{V}_{\mathrm{oc}}$ and $\mathrm{i}_{\mathrm{sc}}$ represents open circuit voltage and short circuit current, respectively.

The conversion efficiency of cell was determined with help of photocurrent and photopotential values at power point (pp) and the power of incident radiation (light intensity $10.4 \mathrm{~mW} \mathrm{~cm}^{-2}$ which is measured by Solarimeter,CEL model SM 203 ), and it was $0.6800 \%$ obtained by using the following formula:

$$
\text { Conversion efficiency }=\frac{\mathrm{V}_{\mathrm{pp}} \times \mathrm{i}_{\mathrm{pp}}}{10.4 \mathrm{~mW} \mathrm{~cm}^{-2} \times \text { Electrode area }\left(\mathrm{cm}^{2}\right)} \times 100 \%
$$

\subsection{Performance of the cell}

The performance of the cell was studied by applying the desired external load ie resistance (carbon pot log $470 \mathrm{~K}$ ) used as rheostate to vary the resistance, necessary to have the potential and current corresponding to the power point, after removing the light source of illumination till the output (power) was reduced to half its value (power $=70.74 \mu \mathrm{W}$ ) at the power point in the dark. The performance was determined in terms of $t_{1 / 2}$ and it was observed that the cell can be used in the dark for 98.0 minutes, which directly indicates the storage capacity of the photogalvanic cell. The observed results are graphically shown in Fig.3.

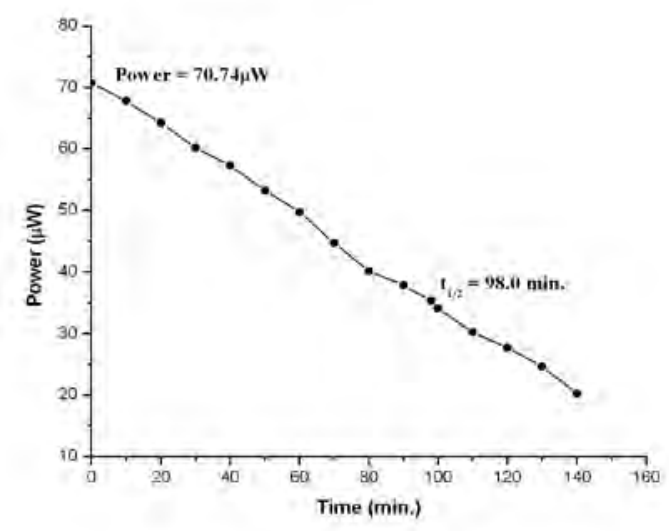

Fig. 3 Performance of the cell

\section{Mechanism}

On the basis of above observations, a tentative mechanism has been proposed for the generation of photocurrent in the cell as follows:

\section{In illuminated chamber}

$$
\begin{aligned}
& \text { Safranine } \stackrel{h v}{\longrightarrow} \text { Safranine }^{*} \\
& \text { Safranine }^{*}+\mathrm{D}-\text { Xylose } \rightarrow \text { D }- \text { Xylose }^{+}+\text {Safranine }^{-} \text {(Semi or leuco) }
\end{aligned}
$$

At platinum electrode 


$$
\text { Safranine }^{-} \rightarrow \text { Safranine }+e^{-}
$$

\section{In dark chamber}

At counter (SCE) electrode

$$
\begin{aligned}
& \text { Safranine }+e^{-} \rightarrow \text { Safranine }^{-} \text {(Semi or leuco) } \\
& \text { Safranine }^{-}+\text {D }- \text { Xylose }^{+} \rightarrow \text { Safranine }+ \text { D }- \text { Xylose }
\end{aligned}
$$

Where safranine* and D-xylose ${ }^{+}$are excited form of dye and oxidized form of reductant, respectively.

\section{Conclusions}

On the basis of the observed results of the photogalvanic cell containing NaLS, safranine and D-xylose system, we have observed that the micelles have not only enhanced the conversion efficiency but the performance of the cell also. Exhaustive efforts still have the scope to enhance the electrical output as well as performance of the photogalvanic cells alongwith reduction in their cost to make commercial viability.

\section{References}

[1] K. Becquerel, on electric effects under the influence of solar radiation, C. R. Acad. Sci., 9, 1839, 561

[2] E. K. Rideal, and E. G. Williams, The action of light on the ferrous iodine iodide equilibrium, J. Chem. Soc.,127, 1925, 258-269

[3] E. Rabinowitch, The photogalvanic effect I: The photochemical properties of the thionineiron system. J. Chem. Phy., 8, 1940, 551-559

[4] Wendell M. Graven, Robert E. Salomon, and George B. Adams, Photogalvanic and photovoltaic effects with anodized zirconium and niobium electrodes, At. Energy Comm. TID-6514, 1960, 45-45

[5] D. E. Hall, William D. K. Clark, J. A Eckert, N. N Lichtin and P. D.Wildes, A photogalvanic cell with semiconductor anode, Ame. Ceramic. Soc. Bull., 56(4), 1977, 408

[6] O. Alfredo, P. Georgina and P. J. Sebasteian, Electron transfer via organic dye for solar energy conversion, Solar Energy Materials \& Solar Cells, 59, 1990, 137-143

[7] M. Mukhopadhyay and B. B. Bhowmik, Kinetics of photoinduced electron transfer in a phptoelectrochemical cell consisting of thiazine dyes and Triton X-100 surfactant, J. Photochem. Photobiol. A: Chem., 69, 1992, 223-227

[8] J. Bisquert, D. Cahen, G. Hodes, S. Riihle and A. Zaban, Physical chemical principles of photovoltaic conversion with nanoparticles, mesoporous dye-sensitized solar cells, J. physical chemistry B, 108, 2004, 8106-8118

[9] G. J. Meyer, Molecular appraaches to solar energy conversion with coordination compounds anchored to semiconductor surfaces, Inorganic Chemistry, 44, 2005, 68526864 
[10] S. C. Ameta, S. Khamesra, M. Bala and K. M. Gangotri, Use of micelles in photogalvanic cell for solar energy conversion and storage, Phill. J Sc., 119(4) 1990, 371373

[11] S. Khamesra, S. Lodha, N. K. Jain and S. C. Ameta, Use of micelles in photogalvanic cell for solar energy conversion and storage: azur C-glucose system, Polish Journal of Chemistry, 65(2-3), 1991, 473-448

[12] S. Pramila and K. M. Gangotri, Use of anionic micelles in photogalvanic cells for solar energy conversion and storage: Dioctylsulfosuccinate-Mannitol-Safranine system, Energy Sources, Part A., 29, 2007, 1253-1257

[13] K. M. Gangotri and P. Gangotri, Studies of the micellar effect on photogalvanics: Solar energy conversion and storage-EDTA-Safranine O-Tween-80 system, Energy \& Fuels, 23, 2009, 2767-2772

[14] K. R. Genwa and Mahaveer, Photogalvanic cell: A new approach for green and sustainable chemistry, Solar Energy Mat. \& Solar Cells, 92(5) 2008, 522-529

[15] A. K. Jana and B. B. Bhowmik, Enhancement in power output of solar cell consisting of mixed dye, J. Photochem. and Photobio. A, 110, 1997, 41-46

[16] K. M. Gangotri and C. Lal, Studies in photogalvanic effect and mixed dye system: EDTA-Methylene blue-Toluidine blue system, Int. J. Energy Res., 24, 2000, 365-371

[17] C. Lal, Use of mixed dyes in a photogalvanic cell for solar energy conversion and storage: EDTA - thionine - Azur B system, J. Power Sources, 164(2), 2007, 926-930

[18] S. Dube, Simultaneous use of two reductants in a photogalvanic cell for solar-energy conversion and storage, Int. J. Energy Res., 17(4), 1993, 311-314

[19] K. M. Gangotri and V. Indora, Studies in the photogalvanic effect in mixed reductants system for solar energy conversion and storage: Dextrose and EDTA-Azur A System, Solar Energy, 84, 2010, 271-276

[20] K. R. Genwa, Arun Kumar and Abhilasha Sonel, Photogalvanic solar energy conversion: study with photosensitizers Toluidine Blue and Malachite Green in presence of NaLS, Applied Energy, 86, 2009, 1431-1436

[21] K. M. Gangotri and P. Gangotri, Studies of the micellar effect on photogalvanics: Solar energy conversion and storage-EDTA-Safranine O-CTAB system, The Arabian Journal for Science and Engineering, 35(1A), 2010, 19-28

[22] S. Yadav and C. Lal, Photogalvanic cells as a device for solar energy conversion and storage: An EDTA-New Methylene blue and Safranine O system, Energy Sources, Part A, 32, 2010, 1028-1039

[23] K. M. Gangotri and M. K. Bhimwal, Study the performance of photogalvanic cells for solar energy conversion and storage: Rose Bengal-D Xylose-NaLS system, Solar Energy, 84(7), 2010, 1294-1300

[24] K. M. Gangotri P. P. Solanki and M. K. Bhimwal, Use of anionic micelles in photogalvanic cells for solar energy conversion and storage storage: Sodium lauryl sulphate-Mannose-Brilliant cresyl blue system, Energy Sources: Party A, 2010, accepted.

[25] K. M. Gangotri and P. P. Solanki, Use of Sodium lauryl sulphate as a surfactant in photogalvanic cell for solar energy conversion and storage: Sodium lauryl sulphateMethylene blue-Mannose system, Energy Sources: Party A, 2010, accepted. 